Regards sur l'économie allemande

Bulletin économique du CIRAC

$73 \mid 2005$

Varia

\title{
Retraites : fusion des caisses publiques le 01-10-05
}

Isabelle Bourgeois

\section{OpenEdition}

Journals

Édition électronique

URL : http://journals.openedition.org/rea/225

DOI : $10.4000 /$ rea. 225

ISBN : 978-2-8218-0842-3

ISSN : 1965-0787

Éditeur

CIRAC

Édition imprimée

Date de publication : 1 octobre 2005

Pagination : 37-38

ISSN : 1156-8992

Référence électronique

Isabelle Bourgeois, «Retraites : fusion des caisses publiques le 01-10-05 », Regards sur l'économie allemande [En ligne], 73 I octobre 2005, document 2, mis en ligne le 06 juin 2008, consulté le 15 septembre 2020. URL : http://journals.openedition.org/rea/225

Ce document a été généré automatiquement le 15 septembre 2020.

(C) CIRAC 


\title{
Retraites : fusion des caisses publiques le 01-10-05
}

\author{
Isabelle Bourgeois
}

\section{Une seule entité : la Deutsche Rentenversicherung}

1 Le dernier volet (Loi de réforme de l'organisation: Gesetz zur Organisationsreform) des réformes des retraites adoptées sous les gouvernements Schröder I et II est entré en vigueur le $1^{\text {er }}$ octobre 2005. Les cinq caisses gestionnaires du système public des retraites ont fusionné pour constituer une nouvelle entité, la Deutsche Rentenversicherung (www.deutsche-rentenversicherung.de). L'objectif de cette réorganisation est de réduire les coûts administratifs de $10 \%$ en cinq ans, soit d'un volume total de 350 millions $€$.

\section{Elle coiffe 2 organismes gestionnaires à l'échelon fédéral}

2 Sont désormais réunies sous le même toit: la Caisse d'assurance des employés Bundesversicherungsanstalt für Angestellte (BfA), les trois caisses sectorielles que sont la Bundesknappschaft (secteur minier), la Bahnversicherungsanstalt (ferroviaire) et la Seekasse (transports maritimes), ainsi que la fédération des 22 caisses régionales (Landesversicherungsanstalten, LVA), la Verband Deutscher Rentenversicherungsträger (VDR). La nouvelle superstructure ne comprend plus que deux organismes gestionnaires à l'échelon fédéral : d'une part la Deutsche Rentenversicherung Bund où sont fusionnées BfA et VDR; d'autre part, la Rentenversicherung Knappschaft-Bahn-See où sont fusionnées les caisses sectorielles. A l'échelon régional, les LVA sont appelées à intensifier leur coopération (effets de synergie), voire à fusionner à l'instar de celles de Berlin et du Brandebourg. 


\section{Une gouvernance soumise à des critères qualité}

3 La quête d'efficience et d'une plus grande proximité avec les assurés se traduit par un nouveau pilotage interne : fonctions et directions transversales sont ainsi concentrées et centralisées dans le but d'une harmonisation verticale des procédures et d'une simplification des procédures financières. Celles-ci sont largement dématérialisées grâce à la mise en œuvre de l'outil informatique dans le cadre du programme de gouvernement électronique Bundonline 2005 (voir REA 61/03). S'y ajoute la mise en œuvre d'un processus permanant de définition de critères qualité (best practices).

\section{Autonomie administrative renforcée}

En troisième lieu, l'autonomie administrative (voir REA 72/05) de la nouvelle entité est renforcée. Les membres de la Deutsche Rentenversicherung, eux-mêmes sous le régime de l'autonomie administrative, sont représentés à l'échelon de la 'holding' via son assemblée, instance co-dirigeante aux côtés du directoire. La majorité de ses membres (60 sur 106) est élue paritairement par les représentants des partenaires sociaux qui administraient l'ex-BfA, de loin l'organisme gestionnaire le plus important, puisqu'il compte 25 millions d'assurés et 8 millions de retraités. Les autres membres sont désignés par les LVA et les ex-caisses sectorielles. Cette hypertrophie représentative, qui amène la presse à taxer la nouvelle holding de "mammouth administratif », est toutefois limitée dans le temps. En 2011, l'assemblée verra se réduire le nombre de ses membres à 60 , soit 30 pour chacun des deux organismes gestionnaires à l'échelon fédéral.

\section{Un seul critère de gestion : le numéro d'assuré}

5 Pour les assurés, la réorganisation n'apporte aucune modification dans la pratique, si ce n'est une plus grande transparence. Ils conservent en effet leur interlocuteur régional ou sectoriel qui, lui, assure désormais une fonction de guichet unique pour le conseil comme la gestion ou transmission des dossiers. Car la réforme a modernisé et simplifié celles-ci en retenant pour seul critère le numéro d'assuré délivré lors de l'affiliation à une caisse de retraite. Ajoutée à la concentration des structures, cette mesure supprime la différenciation qui prévalait jusqu'ici entre ouvriers et employés (ces derniers sont de loin les plus nombreux), mais aussi entre branches ou secteurs.

6 C'est là que réside la véritable portée de la réorganisation des caisses publiques de retraites : elle dépasse la logique de branche sur laquelle repose encore l'ensemble du système de protection sociale allemand, et pas seulement la régulation du travail. Cette réforme avait été co-décidée par les fédérations patronales et syndicales. Elles ont trouvé là une manière de préserver leur partenariat dans le modèle social allemand tout en l'adaptant aux mutations profondes du contexte économique. 